\title{
Estrategias de restauración de ecosistemas en un sitio degradado del bosque húmedo premontano transición seca
}

\author{
Verónica Bonilla Villalobos \\ Escuela de Ciencias Exactas y Naturales, Maestría en Manejo de Recursos Naturales, Universidad Estatal a Distancia, \\ código postal POBOX 474-2050 Mercedes Montes de Oca San José, Costa Rica; veronicabonillav@gmail.com
}

Recibido: 11 de marzo de 2018

Aceptado: 05 de abril de 2018

\section{RESUMEN}

Estrategias de restauración de ecosistemas en un sitio degradado del bosque húmedo premontano transición seca. La finca Los Llanos está ubicada en La Garita de Alajuela, Costa Rica. Se analizó la estructura y composición de la vegetación leñosa de un ecosistema degradado del bosque húmedo premontano transición seca, donde se establecieron 20 parcelas circulares $\left(500 \mathrm{~m}^{2}\right.$ cada una) para el muestreo de los árboles con DAP $>10 \mathrm{~cm}$. Se identificaron 76 individuos pertenecientes a 18 especies y 16 familias, con estos resultados se buscó identificar espacios para proponer áreas de transición. Para ello se generaron criterios para la selección de especies de flora que se recomienda utilizar. Se analizaron los beneficios de los servicios ecosistémicos y la relación costo-beneficio que presentan para Los Llanos, con esto robustecemos la propuesta y se obtuvieron seis áreas de mejora vegetativa (área de conservación; transiciones de pastos a bosque en humedal estacional; restauración de bosques ribereños; pastos a pastos con árboles; pastos a árboles con cultivos y restauración de cercas vivas) con sus acciones de implementación. Además, se establecen acciones que permitan dar seguimiento, monitoreo y control en los procesos de restauración y se visualizan la barreras de esta en tres niveles: social, económica y ambiental. Todos estos criterios y propuestas se basan en las características morfológicas y ecofisiológicas específicas de las especies vegetales, como follaje abundante y fuerte, tipo de propagación, sistema radicular, que sean de rápido crecimiento, resistentes a la sedimentación; especies pioneras, que sean fuertes a la resistencia de plagas y resistentes al fuego, tipo de suelo, entre otros. Esta investigación generó un documento base para dar inicio al proceso de restauración en esta zona de vida.

Palabras clave: Transiciones; Los Llanos; barreras de restauración; monitoreo; especies clave.

\begin{abstract}
Strategies for restoration of ecosystems in a degraded site of the premontane wet forest transition to basal
\end{abstract}

Los Llanos farm is located in La Garita de Alajuela, Costa Rica. The structure and composition of the woody vegetation of a degraded ecosystem of the premontane humid transition dry forest was analyzed, where 20 circular plots (500 $\mathrm{m}^{2}$ each) were established for the sampling of trees with WTP> $10 \mathrm{~cm}$. We identified 76 individuals, 18 species, 16 families and, with these results we sought to identify spaces to propose areas of transition. To do this, criteria were generated for the selection of flora species that are recommended to be used.We analyzed the benefits of ecosystem services and the cost-benefit relationship present in Los Llanos, with this we strengthen the proposal and created six transitions (conservation area, transitions from pastures to forest in seasonal wetlands, restoration of riparian forests, pastures to pastures with trees, pastures to trees with crops and restoration of live fences) with their implementation actions. In addition, actions were established in order to allow monitoring and control in the restoration processes and visualizing the barriers of restoration in three levels: social, economic and environmental. All these criteria and proposals are based on the specific morphological and ecophysiological characteristics of plant species, such as abundant and strong foliage, type of propagation, root system, growing rate, resistance to sedimentation; pioneer species, resistance of pests and fire and type of soil, among others. This research generated a basic document to start the restoration process in the area.

Key words: Transitions; Los Llanos; restoration barriers; monitoring; key species.

\section{Introducción}

El bosque húmedo premontano transición seca se caracteriza por presentar suelos 
volcánicos fértiles (Fournier, 1985), este ecosistema constituye, después del bosque tropical seco el tipo de bosque más alterado y reducido de Costa Rica (Cascante et al., 2001, Amador, 2003, Rodríguez y Brenes, 2009). Probablemente, esto es la consecuencia de que las condiciones climáticas de este tipo de bosque son propicias para la agricultura y el asentamiento de poblaciones humanas, por lo que se ha convertido en el área más desarrollada del país en términos sociales y económicos.

La restauración ecológica (RE) es un proceso inducido por el ser humano para recuperar las condiciones ambientales de un ecosistema perturbado (Sol, Zenteno et al. 2002; Meli, 2003; SER 2004). La meta final del proceso no es recuperar de forma integral el estado anterior pero sí garantizar las funciones de los procesos ecológicos al ecosistema original a través del tiempo (Gálvez, 2002 y Celentano, 2010); este proceso incluye la recuperación de hábitat para la biodiversidad y la provisión de bienes y servicios ecosistémicos (Celentano, 2010).

En el ámbito internacional muchos países son vanguardistas en materia de restauración ecológica. Por ejemplo, en Colombia se ha creado La Red Colombiana de Restauración Ecológica, además del Plan Nacional de Restauración Ecológica y las estrategias nacionales para la restauración ecológica del sistema de parques nacionales, entre otras; en Guatemala, la Universidad Rafael Landivar de la Facultad de Ciencias Ambientales y Agrícolas, ha establecido una serie de documentos técnicos.En México existen las políticas públicas de la restauración ambiental, así como propuestas de RE en áreas afectadas por infraestructura del transporte; manuales sobre la RE para las riberas, entre otras; en España se pueden localizar proyectos sobre seguimientos de restauración de ecosistemas, canteras, entre otros.

En la región centroamericana, Guatemala promulgó en el año 2015, por medio del Decreto Ejecutivo número 2-2015, la Ley de Fomento al Establecimiento, Recuperación, Restauración, Manejo, Producción y protección de bosques en Guatemala, conocida también como la ley Probosques (CENAJOD, 2018). Esta ley tiene por objeto aumentar la cobertura forestal de Guatemala por medio de la creación y aplicación de un Programa de Incentivos que permitan recuperar, restaurar y manejar la producción y protección del bosque y con ello los servicios ambientales que éstos proveen al ser humano (Acosta, Rodríguez, 2015).

En Costa Rica se han hecho esfuerzos sobre este tema. Este concepto de restauración ecológica es introducido al país a mediados de los años 1980 y es considerado como un instrumento para la conservación de la biodiversidad; se realizó un proyecto que culminó con el establecimiento del Parque Nacional Guanacaste y la obtención de recursos para su operación, es el mayor esfuerzo nacional de restauración (INBIO, s.f. a).

La restauración ecológica de hábitats degradados es un proceso difícil, debido a la complejidad de interrelaciones y elementos que están presentes; el objetivo principal es recuperar la función, estructura y composición de un ecosistema degradado por las actividades humanas (Fernández 2006; Clewell y Aronson 2008). Sin embargo, no existen recetas para restaurar un ecosistema, se pueden encontrar recomendaciones generales con bases teóricas y conceptuales proporcionadas por medio de las experiencias acumuladas a través de la historia en ecosistemas del mundo (Vargas, 2011).

Con este estudio se pretende identificar estrategias de restauración para el ecosistema bosque húmedo premontano transición seca, en una finca fragmentada y degradada por medio de la técnica de transiciones.

\section{Materiales y métodos}

Área de estudio: La investigación se desarrolló en la Finca Los Llanos, la cual presenta una cobertura boscosa muy degradada (Alajuela, La Garita, 958'44.94” N, 84¹8'7.056” W, 500 m.s.n.m), está compuesta por pastizales y alguna vegetación arbórea nativa muy dispersa, por lo que se puede considerar un sitio degradado. La degradación del suelo por el uso extensivo de la ganadería y los monocultivos (caña, cacao) que se presentó anteriormente en la propiedad 
(RECAS, 2014) ocasionando la pérdida de la cobertura boscosa (Fig. 1).

La finca Los Llanos cuenta con una extensión de 9.6 hectáreas (ha), colinda con la comunidad del mismo nombre, cuyos pobladores han utilizado la propiedad para diversas actividades de aprovechamiento de servicios ecosistémicos, tales como recreación, captación de agua para consumo y aprovisionamiento.

Esta finca fue cedida en préstamo a la Universidad Estatal a Distancia (UNED) por medio de la figura legal de convenio Comodato por el Instituto Mixto de Ayuda Social (IMAS), según convenio firmado el 22 de marzo, 2018, sin embargo, en sesión 281-06-2013, se había acordado donar a la UNED dicho terreno. La misma colinda al norte, este y oeste con una propiedad de la Hacienda Siquiares Ltda. y la Asociación de la Vivienda, Garita; al sur con la calle pública de Los Llanos y con la propiedad privada de Rafael Sandoval Brenes (IMAS, 2013). Por otra parte, la finca presenta una cobertura de la tierra mayoritariamente conformado por pastizales con algunos relictos de vegetación arbórea nativa.
Análisis y recolección de datos: Se realizó un análisis espacial donde se evidenció que existen una serie de porciones de tierra degradadas, las cuales fueron seleccionadas para incluirlas en los procesos de restauración, mediante el establecimiento de transiciones o procesos de mejora que se realizan en un área. Se establecieron al azar 20 parcelas circulares de muestreo de $500 \mathrm{~m}^{2}$ cada una (radio 12,56 m), donde se contabilizaron y identificaron todas las especies de plantas con un diámetro (DAP) mayor o igual a $10 \mathrm{~cm}$.

Para la definición de estas parcelas se utilizó la herramienta Hawths Tools v3.27 (2006) la cual integrada al programa de sistema de información geográfica, ArcGis v10.3, por medio de los módulos Create Vector Grid y Create Random Selection se crearon cuadrículas correspondientes a las parcelas y con el segundo se seleccionaron al azar. Una vez seleccionadas las celdas al azar se utilizó la herramienta ETGeowizards v11.0 con el módulo Polygon to Point, con el fin de tener la coordenada central
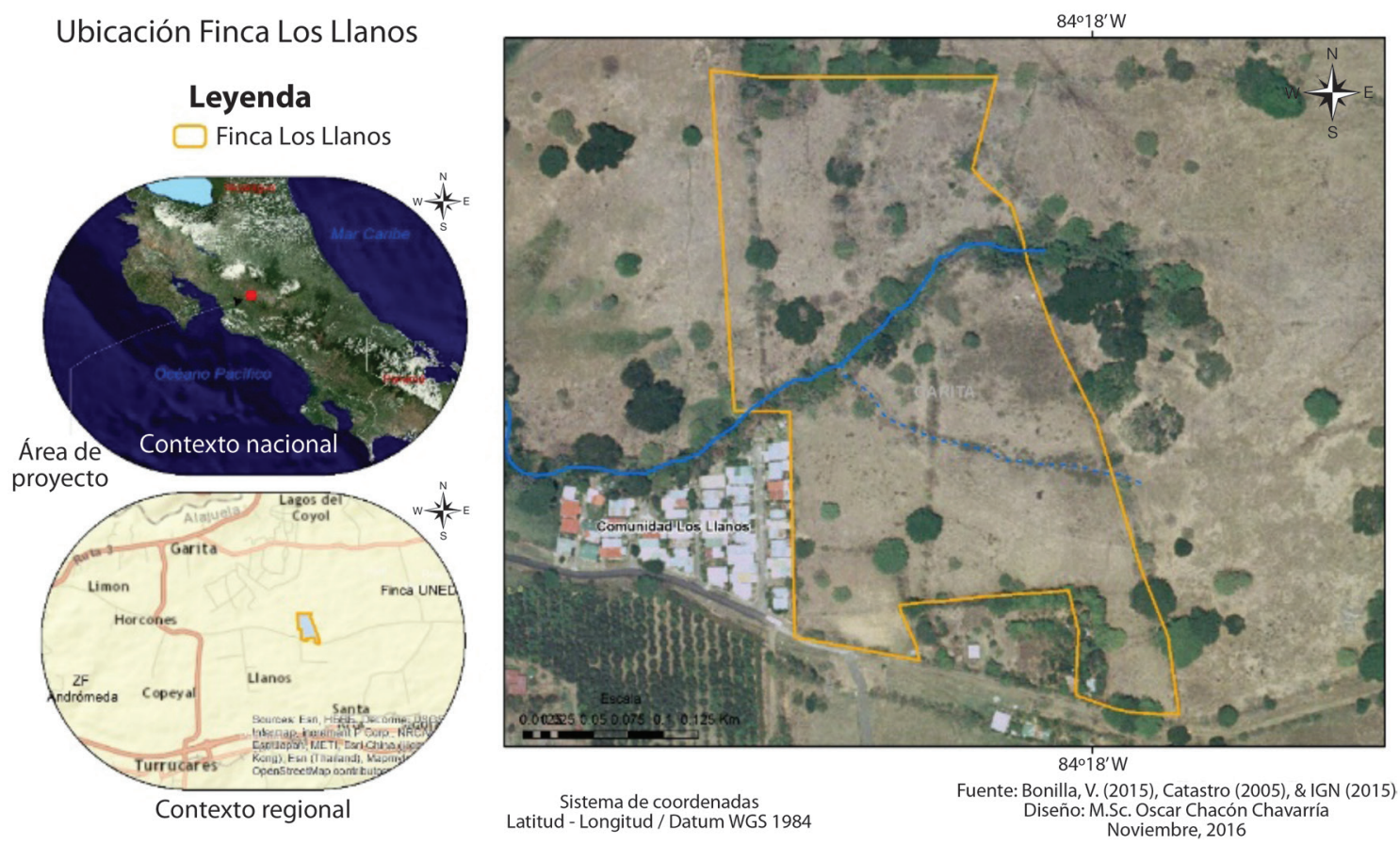

Figura 1. Ubicación espacial de la finca Los Llanos, se muestra el uso del suelo de la Garita; Alajuela, Costa Rica, 2016. 
de cada celda. Estas herramientas se utilizaron en el programa ArcMap 10.3 de Esri.

Una vez identificadas las especies y familias de plantas en cada una de las parcelas, se realizó una exhaustiva revisión bibliográfica para obtener las características morfológicas y ecofisiológicas de las especies identificadas, para así tener un fundamento técnico de sugerencia de especies vegetales a sembrar.

Asimismo, se depura la base de datos estableciendo criterios clave para la selección de las especies de flora. Se utiliza como referencia el valor ecológico y la función que deben brindar las especies como parte del proceso de restauración.

Para establecer áreas de mejora vegetativa (transiciones) se realizaron recorridos y se caracterizó el sitio de estudio definiendo ocho criterios: ubicación en sitios accesibles, falta de cobertura forestal; presencia de nacientes de agua, evidencias de rastros de agua superficial, el estado del suelo, perturbaciones naturales o disturbios, diagnóstico de las comunidades locales y las actividades humanas, intereses comunales y locales y presencia/ausencia de especies clave para el establecimiento de cercas vivas.

Se requirió conocer e identificar los beneficios de los servicios ecosistémicos y la relación costo beneficio que se deben tomar en cuenta a la hora de implemetar las estrategias de restauración. En virtud de lo anterior se proponen acciones que permitan implementar el seguimiento, monitoreo y control en los procesos de restauración.

\section{Resultados}

Se registraron en las 20 parcelas de muestreos 76 individuos de árboles, correspondientes a 18 especies y 16 familias. Todas las familias y especies identificadas son características del bosque húmedo premontano transición seca bhp-Ts (Tabla 1).

Se realizó una caracterización de la propiedad y se identificó que el área de protección del recurso hídrico se distribuye de la siguiente manera: nacientes un $61.27 \%$ (5,82ha), quebrada intermitente $3.34 \%(0,318$ ha) y quebrada
TABLA 1

\section{Familias y especies de árboles representadas en la Finca Los Llanos, la Garita; Alajuela, Costa Rica, 2016}

\begin{tabular}{ll}
\multicolumn{1}{c}{ Familia } & \multicolumn{1}{c}{ Especie } \\
Asteraceae & Vernonia patens \\
Bignoniaceae & Tabebuia rosea \\
Euphorbiaceae & Sapium glandulosum \\
Fabaceae - Mimosoidea & Samanea saman \\
Myrtaceae & Psidium guajava \\
Melastomastaceae & Miconia sp. \\
Moraceae & Maclura tinctoria \\
Malvaceae & Guazuma ulmifolia \\
Moraceae & Ficus sp. \\
Fabaceae & Erythrina berteroana \\
Fabaceae- Mimosoidea & Enterolobium cyclocarpum \\
Rutaceae & Citrus limon \\
Meliaceae & Cedrela odorata \\
Urticaceae & Cecropia sp. \\
Burseraceae & Bursera simaruba \\
Myrsinaceae & Ardisia compressa \\
Fabaceae - Papilionoidea & Andira inermis \\
Anacardiaceae & Anacardium excelsum \\
\hline
\end{tabular}

permanente $35,39 \%$ (3.362ha), por lo cual, según lo establecido en las leyes Forestal N7575, y ley de Aguas $\mathrm{N}^{\circ} 276$ se debe proteger un área total de $64.61 \%$ (6.138ha) (Fig. 2).

Se tomó en cuenta una serie de características para seleccionar especies de flora para la recuperación de la finca como: a) tipo de suelo, b) tipo de follaje, c) sistema de propagación de la planta, y d) sistema radicular. Se requiere que sean especies de rápido crecimiento, resistentes a la sedimentación, especies pioneras, que sean fuertes a la resistencia de plagas y resistentes al fuego, es decir, que presenten una importante capacidad de rebrote.

Tomando en cuenta las características anteriores se establecieron cinco criterios prioritarios relacionados con un alto valor ecológico, como especies de flora formadores del bosque, especies amenazadas, especies que brinden refugio, 


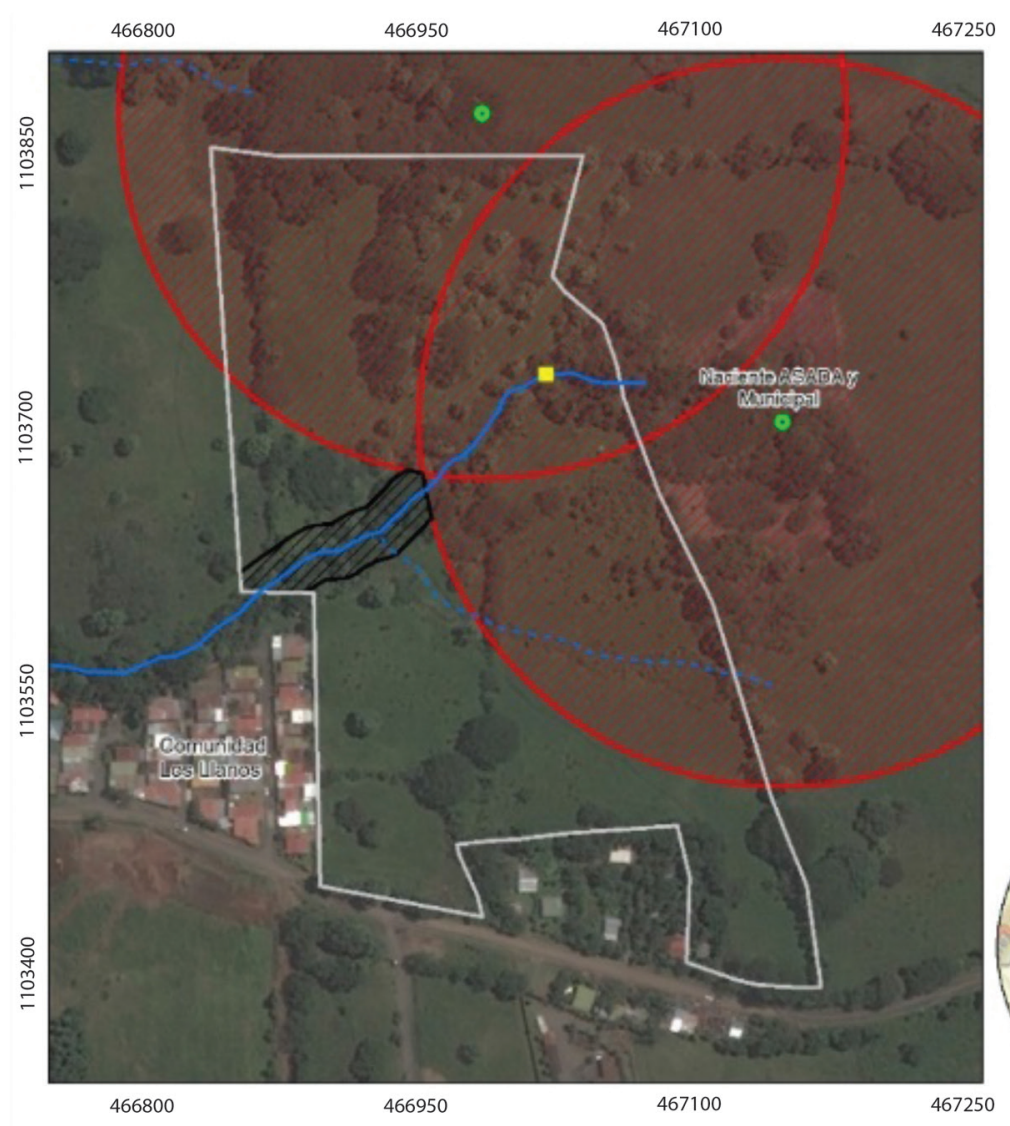

Áreas de protección de nacientes de agua y cuerpo de agua

Simbología

1 Laguna

- Nacientes

Red hídrica

- Permanente

-. - Intermitente

Finca UNED

2 Área de protección de quebrada (15 m) Área de protección de naciente $(200 \mathrm{~m})$
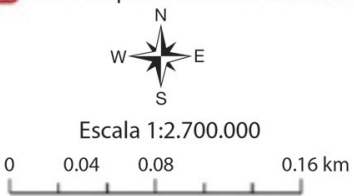

Sistema de coordenadas Costa Rica Transversal Mercator 2005 Datum WGS 1984

Fuente: Bonilla, V. (2015), Bing (2015). Diseño: M.Sc. Oscar Chacón Chavarría Diciembre, 2015

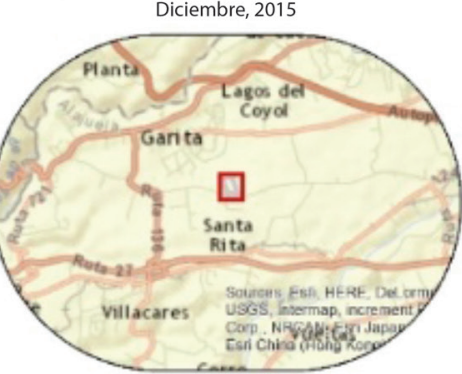

Figura 2. Zonificación del área de protección inmerso en la finca Los Llanos, La Garita, Alajuela, Costa Rica, 2016.

formación y recuperación del suelo y las que presenten algún uso para las comunidades rurales como maderables, frutales, medicinales, cercas vivas u otros (Tabla 2).

Seguidamente se realizó un análisis de los beneficios de los servicios ecosistémicos y la relación costo-beneficio que se deberá tomar en cuenta al implementar las estrategias de restauración y sus transiciones (Tablas 3 y 4).

Asimismo, con los criterios anteriormente mencionandos se establecen seis técnicas de restauración del ecosistema bhP-Ts (Tabla 5). Para desarrollar dichas propuestas se cuenta con un espacio aproximadamente de un $61 \%$ (5.82ha), quedando disponible para otros usos un $39 \%$ (Fig. 3).

Durante el proceso de restauración de un ecosistema se presentan barreras sociales, económicas y ambientales que se deberán solventar para garantizar un buen desarrollo del proceso, para el caso de la finca Los Llanos se determinaron los siguientes acciones:

Social: Incluir la participación comunitaria en los proyectos de restauración, esto genera apropiación y compromisos en mantener la calidad ambiental y social de los ecosistemas, además, estos procesos promueven el trabajo colectivo y propuestas que armonizan objetivos económicos, sociales y ambientales.

La participación de las comunidades locales de una forma directa puede generar empleo local y oportunidades de negocio y capacitación. En muchos casos las comunidades generan conocimiento para la restauración ecológica a través de procesos de investigación participativa. 


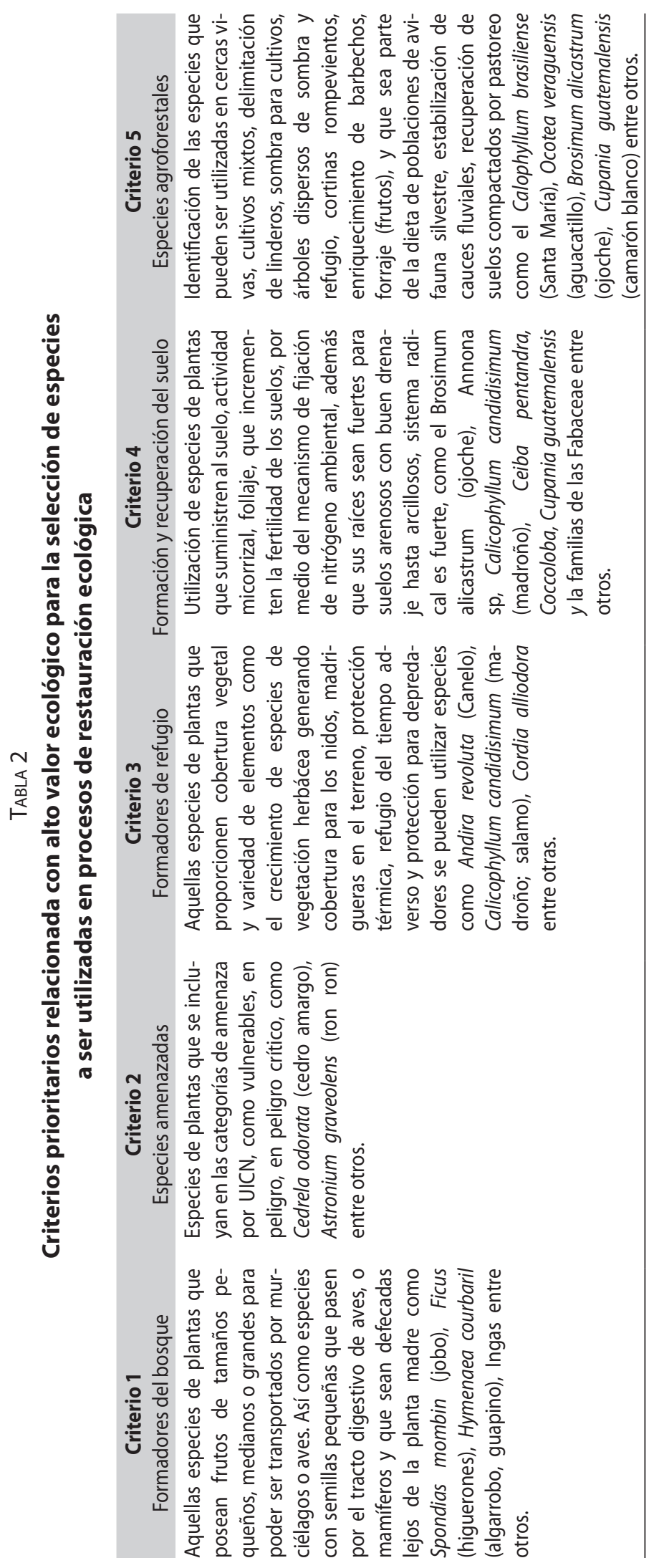


TABLA 3

\section{Beneficios de las actividades de Restauración en el proyecto Los Llanos}

Transiciones

Pastos a Bosques

Pastos a Silvicultura

De cercas de solo postes a cercas vivas

Regeneración Natural

De orillas de ríos sin vegetación a ori-

llas de río con vegetación ribereña
Co-beneficios

Actualmente la finca se encuentra en aproximadamente $90 \%$ cubierta de pastos con árboles aislados; por tanto, las transiciones que se utilicen generarán un incremento de carbono, mejorar la erosión, aumentará la capacidad de retención de agua en el época seca, con el aumento de cobertura forestal ayudará a la polinización y aumentará la biodiversidad (flora y fauna).

Una de las variables que pueden afectar son los incendios forestales, la zona de vida que prevalece es Bosque húmedo premontano transición seca.

Pastos a Pastos con árboles

TABLA 4

Costo-beneficio para las transiciones del proyecto Los Llanos

\begin{tabular}{l}
\multicolumn{1}{c}{ Transiciones } \\
Pastos a Bosques \\
\hline Pastos a Silvicultura \\
\hline De cercas de solo poste \\
a cercas vivas \\
\hline Regeneración Natural \\
\hline De orillas de ríos sin \\
vegetación a orillas \\
de río con vegetación \\
ribereña
\end{tabular}

Pastos a Pastos con árboles

\section{Costos de oportunidad \\ En la actualidad en la finca Los Llanos, no es utilizada bajo ningún uso de suelo, fue en un pasado utilizada para agricultura y ganade- ría. Pero ya desde hace uno años atrás estas prácticas \\ Costos de Transiciones \\ En esta sección los costos son poco tangibles ya que la búsqueda de información es realizada por medio de los investigadores, quienes son los que generan mapas, guías, charlas y demás.} se eliminaron. Sin embargo, en un sector es utilizada por algunos miembros de la comunidad para sembrar, esto sin autorización de la Universidad.

Una vez establecida la propuesta se utilizaran parcelas demostrativas para ser utilizadas en siempre de cultivos.
Se generará convenio con el ICE (Instituto Costarricense de Electricidad) quienes tienen viveros de especies nativas. Convenios con otras universidades para que los estudiantes puedan realizar sus trabajos finales de investigación e investigaciones en general.

\section{Costos de implementación}

En esta sección la institución cuenta con investigadores y estudiantes que colaboran en el mantenimiento, seguimiento y monitoreo de las acciones realizas en la finca.

La obtención de las plántulas se manejaran por convenios con viveros, en cuanto a la recolección de semillas y el almacenamiento y producción de estos por medio de la UNED.

Se dará la participación de la comunidad en la viverización y otros proyectos a nivel ambiental.
Establecer un vínculo con las comunidades locales, donde la UNED, pueda apoyar en los procesos de educación no formal, como capacitaciones y talleres en diversas áreas por ejemplo en el manejo de los recursos naturales, recurso hídrico, viverización, uso de abonos orgánicos entre otras.

Económico: Participación e integración de la comunidad en el proceso de construcción de acciones, como la viverización. La vigilancia continua por parte de los miembros de la comunidad; la participación activa de estudiantes en diferentes procesos, para asegurar la sostenibilidad de la restauración ecológica y la participación de académicos de diversas áreas para la construcción de nuevas estrategias. El apoyo institucional es indispensable para el establecimiento de este tipo de proyectos de restauración, se requiere apoyo de la parte administrativa, 


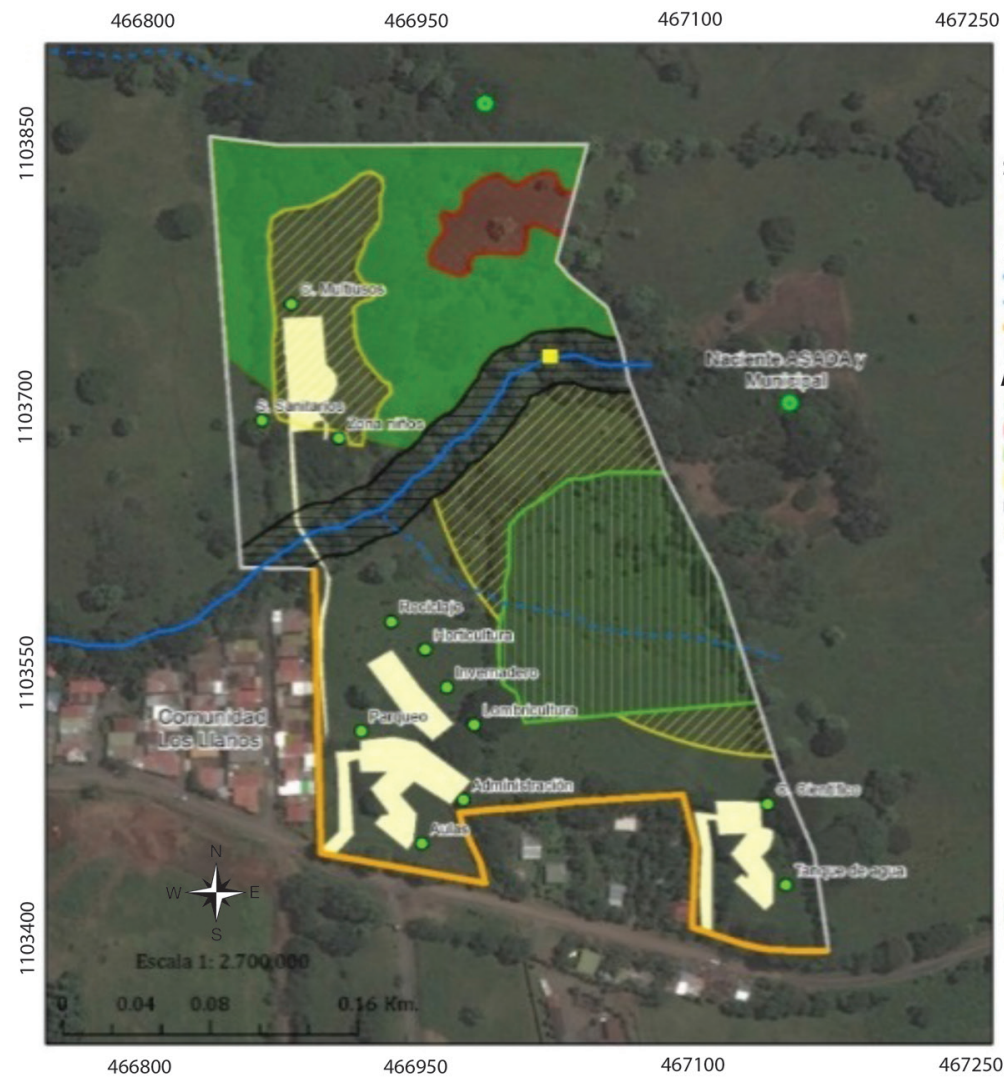

Transiciones de restauración y áreas propuestas a construir según Máster Plan

Simbología

- Laguna

- Nacientes

Red hídrica

- Permanente

-- Intermitente

- Restauración con cercas vivas

Finca UNED

Áreas de restauración/conservación

Conservación

$\triangle$ T. de pastos a bosque en humedal estacional

$\square$ T. de pastos a pasto con árboles con cultivo

T. de pastos a pastos con árboles

అ. restauración bosque ribereño

Propuestas de construcción Máster Plan

Sistema de coordenadas

Costa Rica Transversal Mercator 2005 Datum WGS 1984

Fuente: Bonilla, V. (2015), Bing (2015). Diseño: M.Sc. Oscar Chacón Chavarría Diciembre, 2015

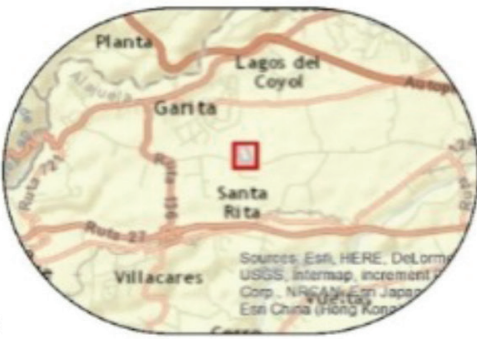

Figura 3. Ubicación de las diferentes zonas en la finca Los Llanos.

presupuestaria y académica. Asimismo, la participación de investigadores y estudiantes internos y externos a la institución es vital para compartir nuevas prácticas y experiencias.

Ambiental: Aseguramiento de estrategias para sobrevivencia de las especies sembradas. Controles y seguimiento de las estrategias implementadas con el fin de dar respuesta inmediata a posibles eventos que pongan en riesgo las inversiones de recursos utilizados para llevar a cabo la RE, incluido un plan de prevención y control de incendios forestales.

Monitorear el proceso de restauración: El monitoreo permanente es considerado como el seguimiento continuo de las acciones desarrolladas en el proyecto. Su propósito es la obtención de información para la toma de decisiones donde se evalúa la trayectoria del proceso de restauración tomando en cuenta los criterios del ecosistema de referencia y las técnicas adaptativas, esto para garantizar el éxito de cada una de las transiciones. En esta investigación se plantean una guía para ser utilizadas y darle seguimiento a los procesos de restauración (Anexo 1).

Asimismo, el monitoreo debe de ser constante durante el desarrollo de las estrategias de restauración que se utilicen en la finca Los Llanos. Las metas y objetivos planteados a corto y mediano plazo se puede valorar por medio del monitoreo de implementación de acciones y las metas a largo plazo para monitorear el funcionamiento o efectividad en el campo; a continuación se presenta una guía.

En cuanto al seguimiento en la estructura, composición y funcionamiento se plantea como estrategia para mejorar la cobertura boscosa mediante la restauración, un control de la recuperación de las transiciones, por medio 
TABLA 5

\section{Propuesta de seis transiciones para la restauración} de sistemas productivos en finca Los Llanos

\begin{tabular}{|c|c|}
\hline $\begin{array}{l}\text { Transición } \\
\text { propuesta }\end{array}$ & Criterio Descripción de la propuesta \\
\hline Conservación & $\begin{array}{l}\text { No se interviene, esta limita con una cerca viva bien establecida, su } \\
\text { estructura física hay un pequeño cerro donde se pueden encontrar } \\
\text { arbustos y algunos árboles dispersos, esta zona se deja como área } \\
\text { control para medir el crecimiento sucesional sin intervención. }\end{array}$ \\
\hline $\begin{array}{l}\text { Pastos a bosque } \\
\text { en humedal } \\
\text { estacional }\end{array}$ & $\begin{array}{l}\text { Por características físicas del lugar, se evidencia cierta tendencia a } \\
\text { formarse un humedal estacional, en épocas de lluvia hay un enchar- } \\
\text { camiento de agua (anegamiento), actualmente está compuesta en su } \\
\text { mayoría por pastos y muy pocos árboles dispersos, los criterios para } \\
\text { la selección de especies para esta sección se basa en Arroyave et al. } \\
\text { (2011); en cuanto adaptación a condiciones de inundación por pe- } \\
\text { riodos cortos, que el sistema de enraizamiento sea vigoroso; utilizar } \\
\text { especies representativas de la zona y de los grupos ecológicos del } \\
\text { bosque de referencia; seleccionar las de mayor importancia ecológica } \\
\text { en los ecosistemas y que la elección de tengan una importancia eco- } \\
\text { nómica que ofrezca atributos para la comunidad; }\end{array}$ \\
\hline
\end{tabular}

Acciones de Implementación

El sistema de siembra deberá facilitar el establecimiento de refugios, zonas de anidamiento y corredores para la movilidad de la fauna local. El sistema de siembra a utilizar puede ser cuadrangular o rectangular, se propone la siembra de especies según los gremios ecológicos las heliófitas efímeras (arbustivas), 5 fuente, 55 individuos por ha; heliófitas efímeras (porte arbóreo) 4 fuentes, 444 individuos, las heliófitas durables (madera) 3 fuentes 111 individuos, para un total de 610 individuos (Scholz et al. 2016); es importante combinar la cantidad de especies recomendadas.

Restauración del bosque ribereño
Esta zona es de especial importancia, se debe de restaurar la parte alta, medio y baja de la ribera dentro de la propiedad. Para cada una de ellas se pueden utilizar estrategias de conservación diferentes, seleccionar árboles pioneros, dominantes y de importancia ecológica para que brinde atributos alimenticios que ayuden a favorecer la llegada de fauna y contribuyan a la dispersión de semillas. Además, especies que presenten mayor abundancia y tiendan a formar núcleos de regeneración que ayuden a la construcción de la estructura vegetación, que sean de crecimiento rápido, sistema radicular profundo, con follaje grande y fuerte entre otras características. Para la parte alta del bosque ribereño se deberá de incorporar especies nativas en ambos lados del borde, esta área presenta una mayor intervención antrópica, a causa de la existencia de varias tomas de agua. En la parte media se encuentran pocos árboles dispersos y las gramíneas son las más predominantes; en una sección del cauce de la quebrada se transforma en una pequeña laguna; pero esta se ha perdiendo por la invasión de gramíneas; y en la parte baja del río; la contaminación por parte de los miembros de la comunidad es evidente y se debe de fortalecer con la siembra de especies de árboles nativos.
Se sugiere utilizar el sistema de siembra cuadrangular o rectangular, aunque se podrían utilizar otras combinaciones de siembra como el lineal, lo importante es equilibrar la distribución de espacios para lograr requerimientos de luz y crecimiento y lograr los estratos del bosque en el menor tiempo. Se propone la siembra de 4 especies heliófitas efímeras (arbustivas) y 4 heliófitas efímeras (porte arbóreo), con un distanciamiento de $3 \mathrm{x}$ 3 ; de las heliófitas durables 3 y 2 esciófitas ambas con un distanciamiento de 4 x 4 (Scholz et al. 2016). 
Tabla 5 (Continuación)

Transición propuesta

Pastos a pastos con árboles
Criterio Descripción de la propuesta

Acciones de Implementación

Esta transición se divide en dos secciones, la parte noreste; un área Para ello se requiere una combinación con árboles y arbustos dispersos y se encuentra inmersa en la transi- de especies de 4 a 6 esciófitas y entre ción de conservación propuesta, es ideónea para establecer áreas de 8 a 12 heliófitas durables; se deberá de recreo (parque lineal) que a la vez funcione como un aula abierta; la utilizar un distanciamiento de 3,5 × 3,5 técnica propuesta para la siembra de especies, puede ser en grupos o metros, aproximadamente 406 indivial azar. En la parte noroeste se plantea utilizar líneas de conservación duos por hectárea en la franja de cosecon franjas de cosecha; lo que se busca es usar las especies madera- cha; con esto se busca integrar un $50 \%$ bles de alto potencial comercial con franjas de conservación. de franjas de conservación esto según Russo, 2016.

Pastos a pastos con árboles con cultivos
En ese sector solamente se encuentran dos árboles dispersos y pas- Técnica de implementación establecen tos, por tanto, se propone utilizar el sistema Taungya, que permita la árboles con cultivos anuales mediante combinación temporal de una plantación con la combinación de cul- hileras de árboles distanciados de 4 a tivos de ciclo corto, como maíz, frijol y hortalizas entre otras, asimis- $6 \mathrm{~m}$ entre hileras y 1 a 3 metros entre mo, se podría implementar dentro del mismo espacio de la transición, árboles, intercalando cultivos anuales la técnica árboles con cultivos anuales; bajo el cultivo en callejones entre hileras de plantación (Russo, 2016). un sistema agroforestal (SAF) en donde de manera simultánea.
Restauración de cercas vivas

\begin{abstract}
A lo largo de toda la Finca Los Llanos; pero especialmente en la zona sury suroeste que da hacia la carretera principal de la comunidad,estas se componen de postes vivos en hileras de árboles o arbustos que delimitan la propiedad o parcelas. El tipo de cercas vivas que se recomiendan son las complejas, en donde hay varias especies presentes, aumentando los estratos de vegetación y la diversidad, aunque también se podrían agrupar según un objetivo secundario, por ejemplo: forrajeras, producción de leña, maderables y multipropósito. Con base en la propuesta de Russo (2016), las características deseables que deben presentar las especies utilizadas para las cercas vivas son: ser rápido crecimiento, de buena propagación vegetativa, alta producción de biomasa (para leña y postes), alta capacidad de rebrote postpoda, compatibilidad con cultivos, entre otras.
\end{abstract}

Para el establecimiento de esta transición en cuanto a las especies se puede hacer por estacas grandes $(1,5$ a $2,5 \mathrm{~m}$ de longitud y 4-12cm de diámetro); algunas de las especie más empleadas como cercas vivas Mangifera indica; Bursera simaruba, spondias spp, Gliricidia sepium, Ficus, Pachira quinata, Simaruba glauca entre otras especies de mediciones y comparaciones entre el estado inicial; el estado actual (con las estrategias incorporadas) y compararlas con el bosque de referencia, con el fin de, darle una evaluación continua e identificar posibles ajustes durante el proyecto; para ello se plantea una propuesta ajustada a los requerimientos de la finca para ser utilizada como una matriz de monitoreo permanente a lo largo del proyecto (Anexo 1).

Seguimiento y Evaluación: Se debe llevar un control para cada una de las transiciones a implementar, preferiblemente digital y utilizando diferentes herramientas como la ubicación por puntos para la siembra o resiembra, con el fin de llevar un manejo estricto de las especies y poder analizar espacialmente el comportamiento de cada una de las secciones, se confecciona una hoja de monitoreo de campo, asimismo, se debe de realizar constraste con lo que se tenía inicialmente y con el control actual.

\section{Discusión}

De acuerdo con Fournier et al. (1985), el Valle Central de Costa Rica, debe contar aproximadamente con 44 a 78 especies forestales por hectárea. La autora de la presente investigación 
TABLA 6

\section{Objetivos de restauración para el monitoreo definido en plazos}

\begin{tabular}{|c|c|c|c|}
\hline Plazo & Objetivo de restauración & Objetivo de monitoreo & Acciones de manejo \\
\hline Corto & $\begin{array}{l}\text { Generar cobertura } \\
\text { vegetal sobre el suelo } \\
\text { (plántulas). }\end{array}$ & $\begin{array}{l}\text { Evaluar el desarrollo de cobertura de } \\
\text { plántulas sobre el suelo. }\end{array}$ & $\begin{array}{l}\text { Incorporación de bancos de semillas } \\
\text { externos (biomasa) }\end{array}$ \\
\hline Mediano & $\begin{array}{l}\text { Generar núcleos de } \\
\text { vegetación arbustiva }\end{array}$ & $\begin{array}{l}\text { Evaluar el desarrollo de transiciones } \\
\text { de vegetación ensamblados con } \\
\text { especies de sucesión temprana }\end{array}$ & $\begin{array}{l}\text { Reemplazo de especies dominantes. } \\
\text { Cambio en las densidades de siembra. } \\
\text { Remoción de especies exóticas si se } \\
\text { requiere. }\end{array}$ \\
\hline Largo & $\begin{array}{l}\text { Enriquecer núcleos } \\
\text { de vegetación con } \\
\text { especies seleccionadas }\end{array}$ & $\begin{array}{l}\text { Evaluar el crecimiento y desarrollo de } \\
\text { plantas de sucesión tardía }\end{array}$ & $\begin{array}{l}\text { Trasplante de ensambles diferentes de } \\
\text { especies. } \\
\text { Entresacas (especies dominantes) }\end{array}$ \\
\hline
\end{tabular}

Fuente: González, Avella y Díaz, 2015; adaptada por Bonilla 2016.

determinó que en la finca Los Llanos el número de especies forestales por hectárea son bastante bajos en cuanto a riqueza de especies, no obstante, las especies identificadas son características de esta zona de vida.

Lo anterior se relaciona con las condiciones de degradación y fragmentación presentes en el sitio, explicados por el uso de suelo actual (deforestación, agricultura y ganadería), a pesar de esto, Los Llanos presenta condiciones muy favorables para la restauración del ecosistema y una de estas condiciones es el recurso hídrico presente. Los autores Sánchez Azofeifa et al. (2001), Cascante et al., (2001) mencionan que tan solo un $21 \%$ del área original del bosque premontano existe actualmente en nuestro país y este presenta un alto grado de fragmentación conformado por pequeños remanentes o islas de bosques.

Es importante tomar en cuenta que no existe un método único para la puesta en ejecución de los procesos de restauración de ecosistemas, especialmente de sitios altamente fragmentados y degradados, la recuperación vegetativa depende de la particularidad de cada sitio (Vargas, 2011). Tomando en consideración esta premisa se proponen una serie de acciones para la restauración de la finca Los Llanos definiendo las características fisiológicas de las especies de plantas que se deberán utilizar para la restauración.
Al mismo tiempo, se proponen cinco criterios para la priorización en la selección de las especies a utilizar, de modo similar Rice y Emery, (2003) hacen referencia a que un atributo clave para la restauración es la reintroducción de especies para mejorar la resistencia y la resiliencias del componente genéticos de los individuos, que son elementos clave entre las estrategias de conservación de especies.

Ahora bien, para la selección de las transiciones se realizó un análisis de los beneficios y co-beneficios de los servicios brindados por el ecosistema, con el fin de tener una visión general del entorno a las estrategias de restauración. Unos de los principales aportes en este proyecto es el establecimiento de estrategias de restauración en la implementación de seis transiciones en la finca Los Llanos. Scholz et al. (2016), mencionan que para garantizar el desarrollo de los procesos de restauración, se debe incrementar la diversidad florística, mejorando la conectividad estructural.

Es imperativo tomar en consideración que en todo proceso de restauración, existen una serie de barreras que pueden impedir su implementación, algunas de acciones a considerar estan inmersas en los procesos sociales, económicos y ambientales, las cuales deben ser solventadas de manera integral, mediante procesos de participación activa y continua de las comunidades. 
Los autores Clewell y Aronson, (2013) mencionan que los proyectos de restauración generan una red de beneficios hacia los sectores sociales, productivos y económicos; por tanto, la participación de la comunidad debe ser continua.

De lo anterior, existen una serie de compromisos de partes para la implementación de las acciones de restauración, en primera instancia la UNED como ente administrador de la Finca Los Llanos tiene la obligación de participar activamente en procesos de socialización y capacitación con la comunidad en proyectos e investigaciones que allí se desarrollen. Asimismo, Smith, Cartaya, Llambi \& Toro, (2013) aseveran que este tipo de proyecto incentiva el trabajo colectivo y desarrolla armoniosamente objetivos sociales, económicos y ambientales.

Por otra parte, la autora propone una serie de acciones para el monitoreo, seguimiento y evaluación de los objetivos establecidos para la restauración ecológica, que permitan medir los avances o retrocesos definidos en la estrategia de restauración, de acuerdo con Vallauri et al. (2005), indican que la restauración ecológica sin monitoreo permanente, no es factible. Estas acciones deberán ser implementadas bajo el marco de un programa de investigación que sea el gestor de diversos proyectos ambientales, sociales y económicos en la finca.

Es así como la autora sugiere incorporar un monitoreo de la vegetación adaptativa, lo que significa que debe incluirse desde el inicio de las estrategias, implementando cuantificadores cualitativos y cuantitativos, fundamentado en lo mencionado por Lindermayer y Liken (2010) quienes centran este principio en incluir nuevo conocimiento a partir de las experiencias, el monitoreo, la investigación y la integración de toda la información; por tanto, se utilizarán parcelas de seguimiento a largo plazo.

Es en proyectos de este tipo, a escala local y de parcelas, donde el monitoreo adaptativo contribuye a tomar acciones que garantizan la dispersión, establecimiento y permanencia de las plantas durante todo el proceso de restauración del ecosistema (González et al. 2015).

\section{Conclusiones}

Se analizaron las diversas propuestas de restauración a escala de paisaje presentes a nivel nacional e internacional y se propone una nueva estructura para ser utilizada como estrategia a escala local o finca. Además, de una guía de técnicas generales de implementación para la restauración ecológica y las estrategias para superar las barreras de restauración.

Se plantea un proceso de seguimiento y monitoreo que se debe de contemplar durante la restauración de Los Llanos y se propone un esquema fundamental para llevar a cabo un proceso de restauración exitoso.

Por medio de la implementación de estrategias de restauración, el proyecto proporcionará mejoras en el recurso natural y calidad de vida a las comunidades aledañas. Involucrando diversidad de técnicas, especialmente la restauración según el área en los sitios clave que permitan la provisión de servicios tales como el agua potable.

Por consiguiente, es necesario utilizar la guía de técnicas para la implementación de restauración ecológica para Los Llanos, con el objetivo de darle seguimiento y ser consecuente con la estructura que se debe de seguir para este propósito.

Del mismo modo, se propone un esquema para obtener la estructura y composición florística y otro donde se visualiza todo el proceso para llevar acabo una restauración ecológica, para una mayor facilidad en la comprensión de los procesos de restauración ecológica para áreas locales.

En el marco de la legislación ambiental en Costa Rica desde su Constitución Política de 1949, en su artículo 50 y la ley Forestal 7575 con la creación de FONAFIFO; se evidencia la necesidad de brindar conocimiento, mejoramiento y conservación de la biodiversidad bajo 
esta presima es necesario llevar acabo la puesta en práctica de este proyecto.

\section{Agradecimientos}

Este trabajo se realizó como parte de los requisitos para que la autora adquiera la Maestría en Manejo de Recursos Naturales de la Universidad Estatal a Distancia optar por el grado de Magister Scientiae con énfasis en Biodiversidad. Wilmar Ovares Villalobos tradujo el resumen al inglés. Un especial agradecimiento al MSc. Johnny Villarreal Orias; MGA. Oscar Chacón Chavarría por sus aportes y ayuda en el proceso de aprendizaje en la investigación sobre restauración.

\section{Referencias}

Acosta Cevallos, E. G., \& Rodríguez Guerrero, B. B. (2015). Influencia del programa socio bosque en la dinámica de los servicios ambientales de los bosques secos deciduos del Ecuador (Master's thesis).

Amador, S. 2003. Principales problemas ecológicos derivados del crecimiento demográfico y la urbanización. Serie: Problemas ecológicos, No 4. San José, Costa Rica. Editorial de la Universidad de Costa Rica. 40p.

Barrientos Z, 2010. Restauración ecológica en la meseta central de Costa Rica, Revista Biocenosis Vol. 23 (2) 2010 .

Cascante A. y Estrada A, 2001, Composición florística y estructural de un bosque húmedo premontano en el Valle Central de Costa Rica, Rev. Biología tropical, 49 (1): 213-225, 2001.

CENAJOD. (2018, Diciembre 12). Centro Nacional de Análisis y Documentación Judicial. Retrieved from Ley de Fomento al Establecimiento, Recuperación, Restauración, Manejo, Producción y Protección de Bosques. PROBOSQUE: http://ww2.oj.gob.gt/es/ QueEsOJ/EstructuraOJ/UnidadesAdministrativas/ CentroAnalisisDocumentacionJudicial/cds/CDs\%20 leyes/2015/pdfs/decretos/D02-2015.pdf

Celenteno D, 2010. Restauración ecológica de bosques tropicales en Costa Rica: Efecto de varios modelos en la producción, acumulación y descomposición de hojarascas; Rev. biol. trop vol.59 n.3 San José Sep. 2011.
Clewell A. F. y J. Aronson. 2013. Ecological restoration: Principles, values and structure of an emerging profession. segunda edición. Island Press. Washington D.C.

Fournier, L., E. Flores y D. Rivera. 1985. Flora arborescente del Valle Central de Costa Rica. San José, Costa Rica. Jiménez y Tanzi, 149 p.

Gálvez, J. (2002). La restauración ecológica conceptos y aplicaciones: Revisión bibliográfica. Guatemala: Universidad Rafael Landivar / IARNAURL. Recuperado de Biblio3.url.edu.gt/IARNA/ SERIETECNINCA/8.pdf

González R, Avella A y Díaz J, 2015, ataformas de monitoreo para vegetación: Toma de y análisis de datos, cap. 2. Monitoreo a procesos de restauración ecológica aplicados a ecosistemas terrestres, edt. Aguilar G y Ramírez, Bogotá, Colombia.

INBIO. (s.f.a). Proyecto de Rearborización del Parque Metropolitano La Sabana. Recuperado en http:// www.inbio.ac.cr/component/content/article/24-inbio/ proyectos/177-proyecto-de-rearborizacion-del-parque-metropolitano-la-sabana.html

Lindenmayer D y Liken G. 2010. The science and application of ecological monitoring. Biological Conservation 143: $1317-1328$.

Meli, P., 2003 Restauración ecológica en bosques tropicales. Veinte años de investigación académica. Interciencia, 8(10):581-589.

Rice, K.; Emery N. C. 2003. Managing Microevolution: Restoration in the Face of Global Change, Frontiers in Ecology and Environment, 1:469-478.

Rodríguez C.; Brenes L; 2009, Estructura y composición de dos remanentes de bosque premontano muy húmero en la reserva Madre Verde, Palmares, Costa Rica, Revista Pensamiento actual, UCR, Vol 9, número12-13 pag. 117- 124 .

Sánchez-Vidal, A. (2001). Medida y estructura interna del sentimiento de comunidad: un estudio empírico. Revista de Psicología Social, 16 (2), 157-175

Scholz C, y Morera Beita A, 2016 Restauración del paisajes forestales, cap. 1, Restauración funcional del paisaje rural: Manual de técnicas, UICN, 2016. Costa Rica.

Smith J. K., V. Cartaya, L. D. Llambi y J. Toro. 2013. Análisis participativo del uso de la tierra y la calidad 
de vida en dos paramos de Venezuela: importancia para el diseño de estrategias de conservación en Cuesta F., J. Sevenik, L. D. Llambi, B. De Bievre y J. Posner (eds.). Avances en investigacion para la conservacion de los paramos andinos. CONDESAN.

Sol A.; Zentendo C; Zamora L; Torres E (2002). Modelo para la restauración ecológica de áreas alteradas. Revista de divulgación Kuxulkab. Recuperado de www.publicaciones.ujat.mx/publicaciones/kuxulkab/ kxul14.html
Vallauri D., J. Aronson y N. Dudley. 2005. An attempt to develop a framework for restoration planning en Mansourian S., D. Vallauri y N. Dudley (eds.). Fores restoration in landscapes. Beyond planting trees. Springer. New York.

Vargas O., 2011. Los pasos fundamentales en la restauración ecológica. La restauración ecológica en la práctica. Memorias del I congreso Colombiano de Restauración ecológica y II Simposio Nacional de experiencias en restauración ecológica. (pp. 19-41). Colombia: Universidad Nacional de Colombia.

\section{ANEXO 1}

\section{Propuesta: Guía técnica general para la restauración de ecosistemas}

Para esta estrategia se utilizará diferentes sistemas de sucesión asistida para las plantaciones, por ejemplo de forma lineal para las cercas vivas, técnica de nucleación para riberas y nacientes como perchas artificiales, siembra directa de semillas, siembra de especies funcionales en grupo de Anderson y la formación de refugios artificiales (madrigueras), entre otras.

Método con sistema de siembra: Realizar el trazado y el establecimiento de la parcela, se puede utilizar cuerdas, estacas o algún otro tipo de material, si el área no está lista, se debe de limpiar antes de empezar, una vez concluida esta etapa se procederá a realizar la siembra manual.

Para la implementación de técnicas en la propuesta del proyecto se consideran diferentes diseños como en líneas, en grupos, al azar, intercalados, entre otros; este diseño va a depender de lo que se requiera realizar y de los árboles preexistentes, uno de los más utilizado es el diseño en líneas (figura 1).

Sin embargo, el sistema de siembra de tresbolillos o pata de gallo (figura 2), es uno de los diseños que se utilizan y se recomienda utilizarlos con un distanciamiento de 3.5 x 3.5 individuos (Scholz y Morera, 2016).

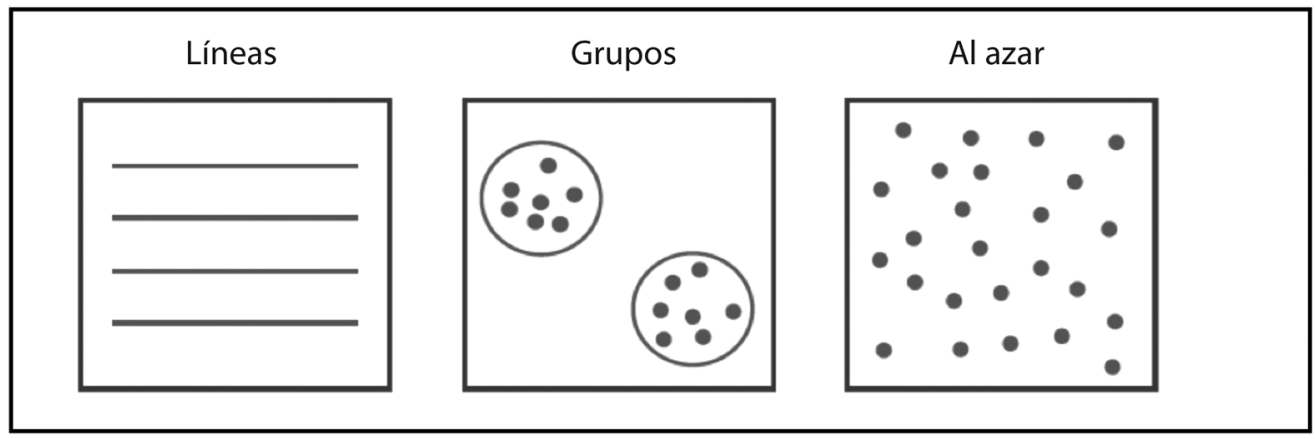

Figura 1. Distintas maneras de siembra; Meli y Carrasco, (2011). 


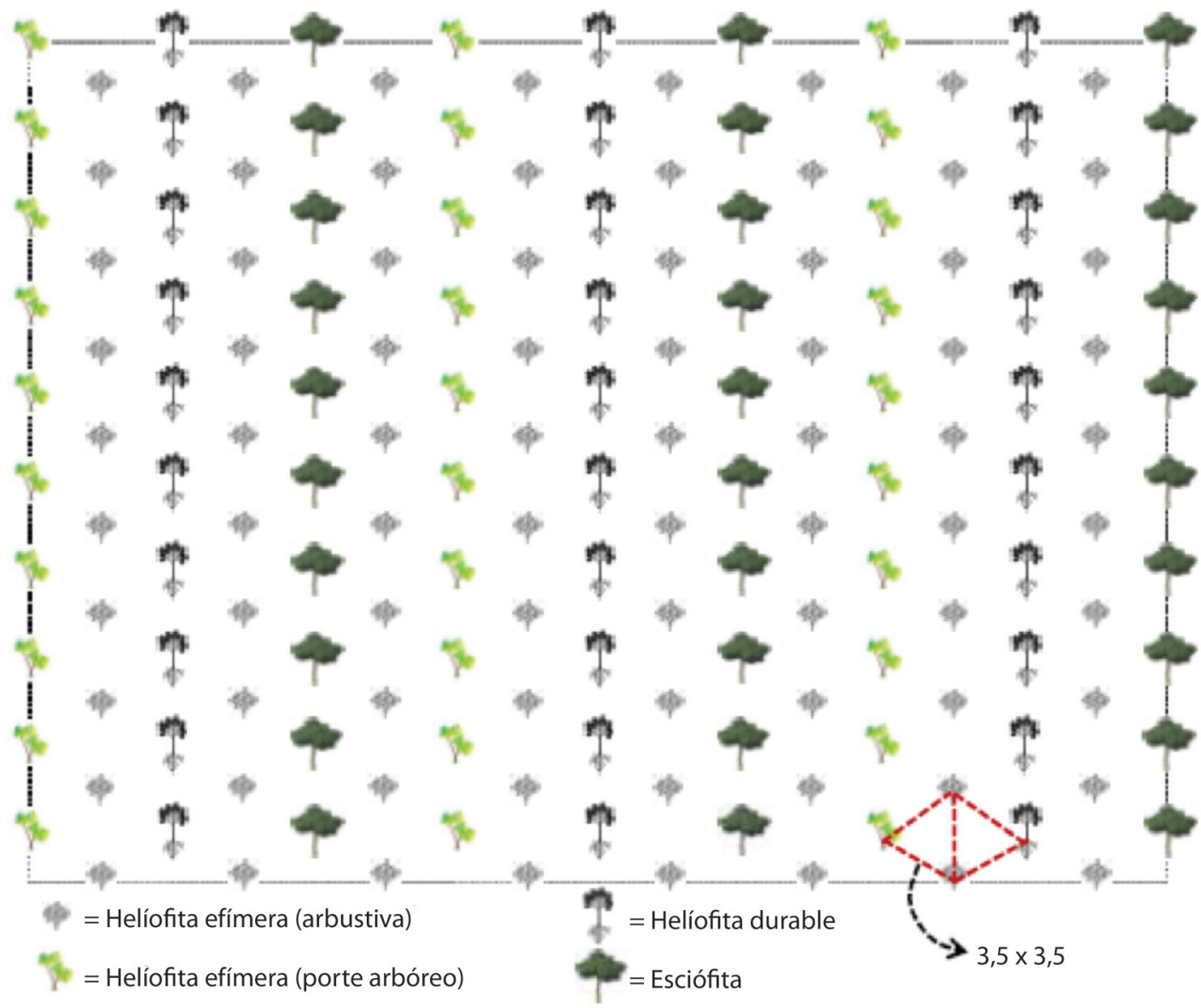

Figura 2. Sistema de siembra tres bolillos Scholz y Morera, (2016).

Los sistemas de siembra rectangular y cuadrangular se utilizan para terrenos planos o con una pendiente menor al 15\%, es una técnica utilizada para la rehabilitación de ecosistemas donde se recomiendan un distanciamiento de 8 x 4 metros y 8 x 8 respectivamente (figura 3), (Scholz y Morera; 2016); sin embargo, Lamprecht (1990), recomienda 3x4 metros y $3 \times 3$ metros (lo que usualmente se utiliza es de 4 x 4 o 6 x 6m); dentro de las técnicas de plantación comercial e indica que si no se efectúa una labranza especial, se deberá realizar hoyos de 60 x 60 x $60 \mathrm{~cm}$ para que las especies puedan desarrollar bien su sistema radicular. 


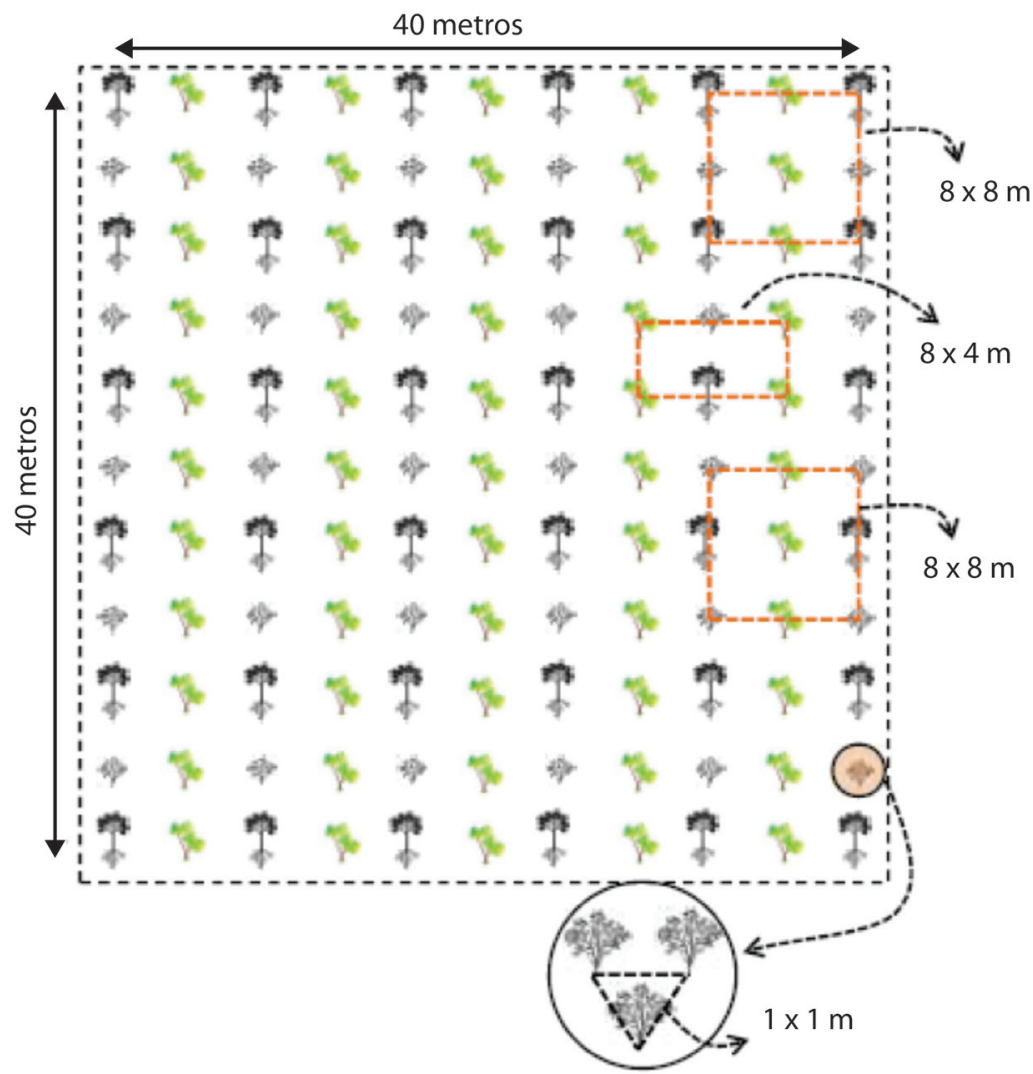

Figura 3. Sistema de siembra en forma rectangular y cuadrangular. Scholz y Morera, (2016).

Se sugiere hacer una combinación de especies con los diferentes gremios ecológicos (tabla 1), tasas de crecimiento y equilibrar la distribución de los espacios para que se formen los diferentes estratos del bosque en el menor tiempo posible.

TABLA 1

Número de individuos y distanciamiento para plantar cada gremio ecológico, según cada sistema de siembra

\begin{tabular}{lcccc}
\multicolumn{1}{c}{ Gremio ecológico } & Especies & Individuos (ha) & Simbogía & Distanciamiento \\
Heliofita efímera (arbustiva) & 3 & 468 & $8 \times 8$ \\
\hline Heliofita efímera (porte arbóreo) & 3 & 312 & $8 \times 4$ \\
\hline Heliofta durable maderable & 2 & 156 & $\mathbf{9 3 6}$ & $8 \times 8$ \\
\hline Total & $\mathbf{8}$ & $\mathbf{9 3 6}$ & \\
\hline
\end{tabular}

Fuente: Scholz y Morera; 2016. 
Es importante tener presente la distancia entre árboles, si se plantan muy cerca reduciría su crecimiento, existen varios métodos de siembra entre ellos:

- Plantación en líneas: Se pueden establecer como una línea simple de árboles o 2 a 3 líneas, en cuyo caso van dispuestas en forma alterna o también utilizar un sistema cuadrangular o rectangular, pueden utilizar como cercas vivas, cortinas rompevientos, protección de quebradas.

- Plantaciones en tresbolillo: Consiste en hacer siembra distribuyendo las especies a distancias iguales formando un triángulo, en los vértices son sembrados los arbolitos; esta forma permite controlar mejor la erosión, por la distribución de las raíces y la buena cobertura que proporcionan las copas de los árboles, para la siembra en campo se debe de utilizar un distanciamiento de 3,5 x 3,5 metros lo que nos da una cantidad total para sembrar por hectárea de 942 individuos, distribuidos por gremios ecológicos (Tabla 2), heliófitas efímeras (arbustiva) 444, heliófitas efímeras (porte arbóreo) 166, heliófitas durables 166, esciófitas 166 individuos por hectárea, ahora bien, podríamos hablar del términos rehabilitación para las zonas de amortiguamiento y utilizar un distanciamiento de $8 \times 8$ ó $8 \times 4$; las heliófitas efímeras se siembran a razón de tres plantas por punto de siembras con un distanciamiento de 1 x 1 metros entre plantas y de 8 x 8 metros entre puntos de siembra, la disposición espacial de las plantas se debe de tener en cuenta a la hora de sembrar las especies y tener el cuidado de no plantar árboles de una mis especies juntas (Scholz y Morera; 2016).

\section{TABLA 2}

\section{Cantidad de especies de acuerdo con el gremio ecológico}

\begin{tabular}{cccccc} 
Área (ha) & $\begin{array}{c}\text { Heliófitas } \\
\text { efímeras arbustivas }\end{array}$ & $\begin{array}{c}\text { Heliófitas efímeras } \\
\text { (porte arbóreo) }\end{array}$ & Heliófitas durables & Esciófitas & Total Especies \\
$1-3$ & $2-4$ & $4-6$ & $4-6$ & $2-4$ & $12-16$ \\
$3-10$ & $3-5$ & $5-8$ & $6-10$ & $4-6$ & $16-24$ \\
\hline
\end{tabular}

Fuente: Scholz y Morera, UICN 2016.

El sitio del proyecto tiene áreas muy diversas, lo cual es importante considerar para programar la restauración ecológica, se sugiere utilizar diversas estrategias de siembra; en los sectores de humedales estacionales se puede trabajar con parcelas; unas lineales, otras cuadrangulares y rectangulares. Con esto se puede hacer una comparación del comportamiento de las especies en diferentes estrategias de manejo; en los sectores denominadas de pastos a pastos con árboles, en el área de ingreso y en la zona de la construcción se pueden seleccionar sectores para la siembra en grupos; en la sección de bosque ribereño y laguna se utilizaría el método de siembra lineal.

Es importante tener presente la mortalidad de algunas plántulas al inicio de la siembra, por lo cual es necesario identificar cuáles fueron las causas y llevar un control o seguimiento minucioso los primeros meses de siembra, además es necesario tomar en cuenta para la siembra de especies la distribución de estas según el gremio ecológico, con el fin de, ir creando los estratos similares a los del bosque Andrómeda y los de la zona de vida boque húmedo premontano transición seca (Tabla 3).

Siembra definitiva y resiembra: La evaluación de sobreviviencia deberá de realizarse un mes después de la siembra y reponer inmediatamente, después de ese tiempo se debe de tomar otras consideraciones, por ejemplo si el porcentaje de mortalidad es menor al $10 \%$ no se justifica replantar e indicar una primera revisión del éxito de la plantación, se indica que del $10 \%$ al $20 \%$ es aceptable, pero se deberá considera la resiembra dependiente de la especie, si la mortalidad es mayor al 20\% indica que hay problemas graves de plantación (Pavón J., Sequeira A., Gutiérrez C., 2003). 
Para llevar a cabo la siembra se debe tener certeza de que las especies forestales están lo suficientemente fuertes y capaces de nutrirse por sí solas; asimismo, en el proceso de seguimiento de las especies sembradas, se debe detectar y llevar un registro de sobrevivencia y mortalidad de las plantas e identificar el factor que causó el desarrollo o la muerte; para poder determinar la necesidad de la resiembra.

TABLA 3

Proceso de siembra y resiembra

\begin{tabular}{|c|c|c|c|}
\hline Fases de las plantaciones & Años & Actividad & Seguimiento \\
\hline $\begin{array}{l}\text { Establecimiento de viveros } \\
\text { y siembra y resiembra. }\end{array}$ & 1 a 4 & $\begin{array}{l}\text { Las plántulas se adaptan a las } \\
\text { condiciones climáticas. } \\
\text { Sembrar alternando efímeras y las } \\
\text { durables y las esciófitas cercanas a } \\
\text { las especies forestales maduras. }\end{array}$ & $\begin{array}{l}\text { Control de mortalidad, deshierba, } \\
\text { abonos, podas y cortafuegos. }\end{array}$ \\
\hline $\begin{array}{l}\text { Crecimiento de las } \\
\text { especies forestales }\end{array}$ & 4 a 10 & $\begin{array}{l}\text { Los árboles inician su crecimiento } \\
\text { en altura, llevar controles de } \\
\text { crecimiento. }\end{array}$ & $\begin{array}{l}\text { Raleos y podas, según su ubicación, } \\
\text { control de enfermedades. Y se pude } \\
\text { Ilevar un seguimiento de las especies } \\
\text { de fauna que utilizan de abrigo, refugic }\end{array}$ \\
\hline Maduración & 10 & $\begin{array}{l}\text { Los árboles empiezan a incrementar } \\
\text { su diámetro, llevar controles de } \\
\text { crecimiento. }\end{array}$ & y alimentación. \\
\hline
\end{tabular}

Nota: Llevar un registro tanto escrito, como fotográfico para evidenciar el proceso de restauración de cada una de las áreas seleccionadas.

Recuperación del suelo: La vegetación asociada corresponde a aquellas especies con tejidos fibrosos que podrían soportar los cambios bruscos de la mecánica del suelo y el déficit hídrico. Plantas heliófilas efímeras y xerofitas, que son especies que requieren alto niveles de luz para su germinación y establecimiento, además, de ser más fuertes y resistentes para este tipo de suelo, son idóneas. También se pueden utilizar las especies heliófitas durables, que son de crecimiento rápido, durante la primera etapa. Una vez establecidas, se procederá a iniciar con la siembra de otras especies.

Para este tipo de suelo se sugiere preparar el terreno mediante una descompactación de 50 o $60 \mathrm{~cm}$ de profundidad; otra técnica menos costosa es solamente realizar una franja donde se van a plantar las especies, estas técnicas ayudan a elevar la tasa de infiltración de manera óptima y reducir la escorrentía superficial, mejorar las condiciones para la penetración de las raíces y eliminar la competencia de la vegetación trastera por agua y por luz (Lamprecht, 1990).

Recuperación del recurso agua: Incrementar la vegetación nativa en los bordes de los cursos de agua y en las áreas de pastos que se encuentran dentro de la zona de amortiguamiento, algunas de estas áreas se encuentran con árboles aislados y otras zonas rocosas.

Para la restauración de riberas y nacientes de agua; se propone como técnicas de implementación; la sucesión asistida a través de técnicas de nucleación, que consiste en utilizar todos aquellos sitios donde el potencial de regeneración es reducida al grado de alteración o deterioro.

Implementar técnicas tales como: perchas artificiales, siembra directa de semillas, siembra especies funcionales en grupos de Anderson y se sugiere realizar combinaciones de estas técnicas; además, de las siembra en líneas y al azar, que también se pueden utilizar.

Medios de reproducción de germoplasma: Al ser la comunidad un agente importante en lo que respecta al objetivo de la restauración, se propone implementar la construcción de un vivero para el 
manejo del material vegetal a utilizar, se requiere la creación de invernaderos o viveros para la propagación y crecimiento, control y seguimiento permanente del germoplasta y plántulas.

En cuanto a los recursos de infraestructura para reproducción de especies, se puede contar con los Centros Universitarios (CEU) de la UNED, utilizando espacios libres para la construcción de viveros forestales, dos de estos CEU (Heredia y Santa Cruz) cuentan con viveros, proyecta trabajar con los CEU's de San Isidro, Ciudad Neily, Buenos Aires, Pavón y Palmares entre otros; asi mismo, otra estrategia es establecer un convenio con Adaptación Social para hacer uso del vivero de la reforma para producir árboles que se requieran para el momento.

Para la obtención del germoplasma se sugiere las siguientes estrategias: a) por medio del vivero forestal FUNDAZOO quien podría proveer material vegetativo, b) la recolección directa de semillas en especies claves identificados en la zona. Para ello es necesario llevar un control estricto en cuanto al germoplasma obtenido en cuanto a cantidades y ubicaciones (para no tener un el mismo ADN de las especies) y c) por medio de viveros forestales cercanos a la zona.

Disponibilidad de especies en la región: en cuanto a la disponibilidad de especies, se realizó una búsqueda de Centros de reproducción de especies que se encuentren aledaño a la finca Los Llanos, dentro de los cuales se presentan algunas opciones (tabla 4).

TABLA 4

\section{Centros de reproducción de especies forestales}

\begin{tabular}{lc}
\multicolumn{1}{c}{ Centro de ventas de plantas } & Teléfonos \\
Vivero Central la Garita & $2433-7364$ \\
Vivero Silvio * & $2487-6795 / 8317-0872$ \\
Vivero Reproductores & $8886-2205 / 8474-1299$ \\
Vivero Laureles & $2433-9595$ \\
Vivero palmeras & $2433-9682$ \\
Vivero Eli & $2433-3715$ \\
Viveros La Llama del bosque* & $8430-7072 / 8382-9995$ \\
Vivero la Esperanza & $8858-9407 / 8890-6461$ \\
Vivero Prosesa Nature** & $2433-9082$ \\
Vivero Forestal de FUNDAZOO & $2282-8434$ \\
\hline
\end{tabular}

* Vivero que cuentan con muchas de las especies requeridas para este proyecto y vivero PROSESA tiene experiencia en este tipo de actividades ya que fueron punto de venta directo del proyecto de restauración de la Parque Metropolitano la Sabana.

Tomando esto dos centros como puntos de referencia para la adquisición de plantas, los costos aproximados rondan entre 5000 y 12000 colones por unidad esto depende de la especies, el tamaño y en grandes cantidades los costos bajan considerablemente.

Para llevar a cabo este punto se tomará como referencia los viveros forestales que se encuentran en la zona, como es el caso del Centro de Conservación Santa Ana, el cual posee un vivero de producción de especies nativas que podrá servir como material de producción inicial.

Es necesario tener presente la disponibilidad de especies en la región, su ubicación, su etapa sucesional, abundancia y variabilidad genética. Es importante tomar en cuenta las especies pioneras, las especies sucesionales tardías, las especies dominantes y codominantes, así como las expecies raras; para esta práctica se debe de tener un inventario de composición de especies y una clasificación de 
las etapas sucesionales para tratar de definir la estructura de las especies dominantes en el ecosistema histórico y en diferentes trayectorias sucesionales (Vargas, 2011).

Monitorear el proceso de restauración: El monitoreo permanente es considerado como el seguimiento continuo de las acciones desarrolladas en el proyecto, con el fin de identificar posibles ajustes en el momento preciso y su propósito es la obtención de información, con el objetivo de evaluar la trayectoria del proceso de restauración, en relación a los criterios del ecosistema de referencia y ayudar en la selección de técnicas adaptativas para asegurar el éxito del cada una de las transiciones, se plantean una sería de guías para ser utilizadas y darle seguimiento a los procesos de restauración.

El monitoreo debe de ser constante durante el desarrollo de las estrategias de restauración que se utilicen en la finca Los Llanos; las metas u objetivos planteados como corto y medianos plazo se puede valorar como monitoreo de implementaciones de las acciones y las metas a largo plazo para monitorear el funcionamiento o efectividad en el campo (Tabla 5).

\section{TABLA 5}

\section{Objetivos de restauración para el monitoreo definido en plazos}

\begin{tabular}{|c|c|c|c|}
\hline Plazo & Objetivo de restauración & Objetivo de monitoreo & Acciones de manejo \\
\hline Corto & $\begin{array}{l}\text { Generar cobertura vegetal } \\
\text { sobre el suelo (plántulas). }\end{array}$ & $\begin{array}{l}\text { Evaluar el desarrollo de } \\
\text { cobertura de plántulas sobre el } \\
\text { suelo. }\end{array}$ & $\begin{array}{l}\text { Incorporación de bancos de semillas } \\
\text { externos (biomasa) }\end{array}$ \\
\hline Mediano & $\begin{array}{l}\text { Generar núcleos de } \\
\text { vegetación arbustiva }\end{array}$ & $\begin{array}{l}\text { Evaluar el desarrollo de } \\
\text { transiciones de vegetación } \\
\text { ensamblados con especies } \\
\text { de sucesión temprana }\end{array}$ & $\begin{array}{l}\text { Reemplazo de especies dominantes. } \\
\text { Cambio en las densidades de siembra. } \\
\text { Remoción de especies exóticas si se } \\
\text { requiere. }\end{array}$ \\
\hline Largo & $\begin{array}{l}\text { Enriquecer núcleos de } \\
\text { vegetación con especies } \\
\text { seleccionadas }\end{array}$ & $\begin{array}{l}\text { Evaluar el crecimiento y } \\
\text { desarrollo de plantas de } \\
\text { sucesión tardía }\end{array}$ & $\begin{array}{l}\text { Trasplante de ensambles diferentes de } \\
\text { especies } \\
\text { Entresacas (especies dominantes) }\end{array}$ \\
\hline
\end{tabular}

Fuente: González, Avella y Díaz, 2015; adaptada por Bonilla 2016.

En cuanto al seguimiento en la estructura, composición y funcionamiento que se plantea como estrategia para mejorar la cobertura boscosas mediante la restauración, un control de la recuperación de las transiciones, por medio de mediciones y comparaciones entre el estado inicial; el estado actual (con las estrategias incorporadas) y compararlas con el bosque de referencia, con el fin de, darle una evaluación continua e identificar posibles ajustes durante el proyecto; para ello se plantea siguiente propuesta adaptada para ser utilizada como una matriz de monitoreo permanente a lo largo del proyecto (Tabla 6). 
TABLA 6

Criterios e indicadores para el monitoreo de la finca Los Llanos

\begin{tabular}{|c|c|c|c|c|c|c|}
\hline \multirow{2}{*}{ Criterios } & \multicolumn{2}{|r|}{ Indicadores } & \multirow{2}{*}{ Cuantificadores } & \multicolumn{3}{|c|}{ Plazo } \\
\hline & Indicador & Análisis & & C & M & $\mathrm{L}$ \\
\hline Composición & $\begin{array}{l}\text { índice de riqueza de } \\
\text { especies }\end{array}$ & Familias - especies & Riqueza ( R) & $x$ & & \\
\hline Composición - Estructura & ïndice de riqueza específica & $\begin{array}{l}\text { Familias - especies - número de } \\
\text { individuos }\end{array}$ & Menhinick (M) & $x$ & $x$ & $\mathrm{x}$ \\
\hline Composición - Estructura & $\begin{array}{l}\text { índice de diversidad y } \\
\text { abundancia proporcional } \\
\text { (equidad) }\end{array}$ & $\begin{array}{l}\text { Familias - especies- número de } \\
\text { individuos }\end{array}$ & Shannon-Wiener ( $\left.\mathrm{H}^{\prime}\right)$ Pieloi $\left(\mathrm{J}^{\prime}\right)$ & $x$ & $x$ & $\mathrm{x}$ \\
\hline Composición - Estructura & $\begin{array}{l}\text { índice de diversidad y } \\
\text { abundancia proporcional } \\
\text { (dominancia) }\end{array}$ & $\begin{array}{l}\text { Familias - especies - número de } \\
\text { individuos }\end{array}$ & Simpson (D) & $x$ & $x$ & $\mathrm{x}$ \\
\hline Composición & índice de disimilaridad & Familias - especies & Bray-Curtis (Djk) & $x$ & $x$ & $x$ \\
\hline Composición - Estructura & $\begin{array}{l}\text { índice de predominio } \\
\text { fisionómico }\end{array}$ & $\begin{array}{l}\text { número de individuos - diametro } \\
\text { cobertura }\end{array}$ & $\begin{array}{l}\text { IPF (área basal relativa, cobertura } \\
\text { relativa, densidad relativa) }\end{array}$ & $x$ & $x$ & $\mathrm{x}$ \\
\hline Estructura & Indice de densidad & $\begin{array}{l}\text { número de individuos -localización } \\
\text { espacial }\end{array}$ & Individos por área & $x$ & $x$ & $x$ \\
\hline Estructura & $\begin{array}{l}\text { Tasa de mortalidad y } \\
\text { reclutamiento }\end{array}$ & Número de individus & $\mathrm{TM}, \mathrm{TR}$ & & & $\mathrm{x}$ \\
\hline Estructura & $\begin{array}{l}\text { Relación de desarrollo } \\
\text { del tallo }\end{array}$ & Diámetro - número de individuos & ICA (diámetro) & & & $\mathrm{x}$ \\
\hline Estructura & $\begin{array}{l}\text { Relación de crecimiento } \\
\text { vertical }\end{array}$ & Altura - número de individuos & ICA (altura) & & $x$ & \\
\hline Estructura & $\begin{array}{l}\text { Factor de ocupación } \\
\text { del espacio }\end{array}$ & $\begin{array}{l}\text { Cobertura de copa - número de } \\
\text { individuos }\end{array}$ & ICA (cobertura) & & & $\mathrm{x}$ \\
\hline Estructura & $\begin{array}{l}\text { Indicador de posición } \\
\text { sociológica }\end{array}$ & $\begin{array}{l}\text { Diámetro - altura - cobertura de copa } \\
\text { - número de Individuos }\end{array}$ & $\begin{array}{l}\text { Distribución por clases diamétricas, } \\
\text { alturas y coberturas }\end{array}$ & $x$ & $x$ & $x$ \\
\hline Composición - función & Valor de existencia & Especies - origen & Nativa - introducida & $x$ & $x$ & \\
\hline Función & Índice de adelanto floral & & Índice de adelanto floral & & & $x$ \\
\hline
\end{tabular}

Fuente: González, Avella y Díaz, 2015; adaptada por Bonilla 2016. Nota: léase C: corto, M: mediano y L: largo plazo.

Seguimiento: Se debe llevar un control por cada una de las transiciones a restaurar, preferiblemente digital y utilizando diferentes herramientas como la ubicación por puntos para la siembra o resiembra, con el fin de llevar un manejo estricto de las especies y poder analizar espacialmente el comportamiento de cada una de las secciones, se confecciona una hoja de monitoreo de campo.

Evaluación del monitoreo: comparación entre los datos obtenidos en bosque de referencia, estado inicial y el estado actual de Los Llanos con los datos obtenidos del cuadro 30, sin embargo, en ese mismo cuadro se le da seguimiento a información nueva que se obtendrá de las plántulas y árboles sembrados.

\section{Propuestas de procesos técnicos en la restauración de un ecosistema a escala local}

Para este estudio se propuso un esquema fundamental donde se establecen una serie de pasos para lograr una restauración ecológica a escala local (Figura 4). 


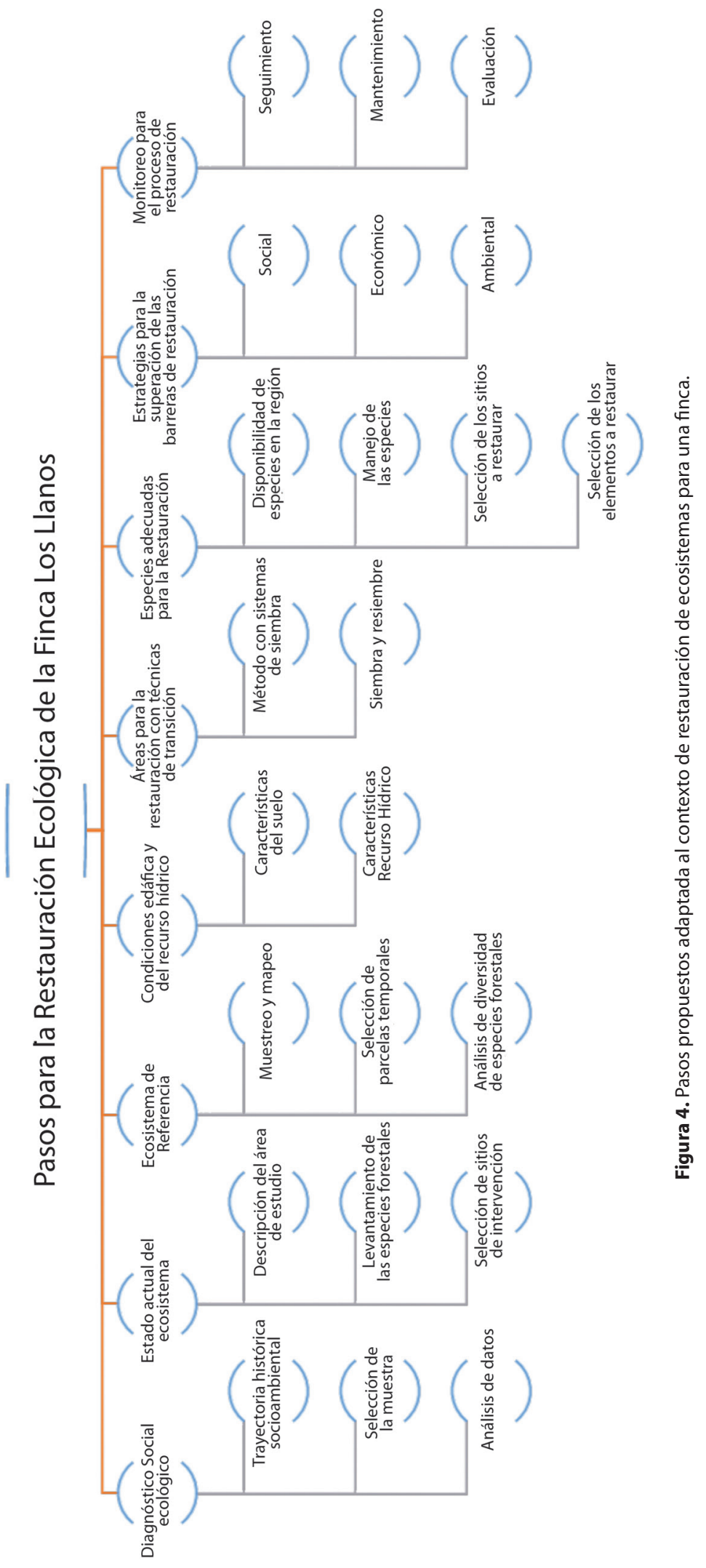

